cine during a two month period in 1985. Although they were not randomly selected, we can see no reason why their prevalence of hepatitis $B$ infection should differ from that in attenders at any other time of year. Our studies were directed towards detecting the hepatitis B carrier state; this is not a transient phenomenon that persists for only a few months. Of course, we do not claim that patients of any race or colour at departments of genitourinary medicine are representative of the general population. The aim of our study was to detect the prevalence of markers of infection with hepatitis B in clinic attenders, as we were interested in the workload generated by specimens from these patients. We are only too aware of the sexual mode of transmission of hepatitis B virus and would have expected the prevalence of markers in clinic attenders to be higher than in the general population. The results showed, however, a high prevalence in native West Indians and not in either the white or negro groups born in the UK.

The native West Indians were generally older than those born in the UK (unavoidable in a parent population) but the mean age of those with markers of previous infection with hepatitis B virus ( 35.7 years) did not differ significantly from the mean age of the whole group (33 years) $(t=1 \cdot 67, \mathrm{p}>0 \cdot 1)$.

The work of others supports the need for screening for HBsAg in native West Indians. ${ }^{12}$ The remarkable finding of our study was the low prevalence of infection in the West Indian descendants born in the UK, even in a "high risk" population from a genitourinary medicine clinic. This must suggest that routine screening for $\mathrm{HBsAg}$ is unnecessary in British born negroes of West Indian descent in Lambeth, at least in the department of genitourinary medicine. Dr Cruickshank has misinterpreted our message. We believe our results are valid for the population we studied and that common sense has as important a part to play in medicine as confidence limits.

M J GODLEY P W LAIDLER

J E BANATVALA

Departments of Genitourinary Medicine and Clinical Virology,
St Thomas's Hospital,

London SE1 7EH

1 Mazzur S, Nath N, Fang C, et al. Distribution of hepatitis B virus (HBV) markers in blood donors of thirteen western hemisphere countries: proceedings of the Red Cross Latin sphere countries: proceedings of the Red Cross Latin
American hepatitis B workshop. Bull Pan Am Health Organ American hepatitis
$1980 ; 14: 44-51$.

2 Barbara J, et al. Hepatitis B in a West Indian population in the United Kingdom. Br Med $\mathcal{F}$ 1986;292:766.

\section{Employees with epilepsy in the NHS}

SIR,_Dr T A Betts's desire to obtain employment for sufferers from epilepsy is well known, and occupational physicians would support him in his efforts. Certain qualifications to the guidelines he quotes in his letter (15 March, p 764) are, however, necessary. Firstly, the guidelines state that a person with epilepsy who is legally entitled to drive shall be deemed fit for employment in any branch of the National Health Service. One branch that would clearly exclude anyone who has had a fit after the age of 5 is the ambulance service. In addition, there are many other driving posts within the NHS that require only someone with a private driving licence but in which it would also be wise to exclude all subjects who have had fits after the age of 5 . I believe Dr Betts will find that the medical advisers at the Driver and Vehicle Licensing Centre would term these "professional drivers" and agree with this exclusion.

Secondly, Dr Betts states that "many medical and surgical tasks do not carry such responsibili- ties"- for example, sole charge of an unconscious patient. Perhaps he needs to be more specific. It would be difficult to find any, let alone many, medical or nursing posts in which a sudden loss of consciousness would not be potentially hazardous to a patient.

Thirdly, although I agree that every opportunity should be given to sufferers to appeal against a refusal or termination of employment on medical grounds, and to ask for a second opinion, in the end the decision must rest with the management, which has the right to accept or reject any medical advice given. Obviously, if the management decides to reject medical advice it risks the matter going to an industrial tribunal, but it still has that right. No doctor, unless he happens to be the manager, may take on this management role.

W G BENSON

Occupational Health Department,

Bristol Royal Infirmary,

Bristol BS2 8HW

\section{Neonatal screening for sickle cell disease in Camberwell}

SIR,-As the white mother of a mixed race child whose father is black (of West Indian origin) I was interested in the pilot study by Dr Mary E C Horn and others (15 March, p 737). I was surprised, however, to see no reference to the self help group, Organisation for Sickle Cell Anaemia Research (OSCAR), ${ }^{1}$ which celebrated its tenth anniversary in 1985, or to any other self help group. Both the Lambeth and Lewisham branches of OSCAR must be close to the Camberwell area where the study took place.

Interestingly, Dr Horn and others did not include for screening those children of white mothers whose father was not white. I assume the reason was that there was no plan to inform parents whose infants were heterozygous unless requested, and this is the only likely abnormal phenotype for an infant with one white parent (almost certainly $\mathrm{HbAA}$ ) and one black parent (possibly HbAS or HbSS). "In the absence of expert counselling routine notification of parents whose infants are heterozygous is of no immediate value and may cause unnecessary anxiety." I suggest that contact with counsellors from OSCAR would have supplied this need.

When at my request my son was screened at 18 months of age I would have wanted to know if he were heterozygous. Because of my medical training my attitude to this may differ from that of non-medical people. I think in general, however, that people want and have the right to know.

I strongly agree that "more emphasis must be placed on sickle cell disease in the education of doctors and nurses and short specialised courses are needed for health visitors undertaking counselling in family planning and antenatal clinics." The need for a "major programme of education and screening ... for the two thirds of a million black people living in Great Britain" is something that should be undertaken in collaboration with the existing agencies, including OSCAR, so that black people may participate in the planning, rather than having them imposed by the health authority, thus recognising the needs that black people are themselves expressing.

The national head office of OSCAR is at 200A High Road, Wood Green, London N22 4HH, and there are other branches in Lewisham, Lambeth, Reading, Walthamstow, Nottingham, Birmingham, and Bristol.

H CoOLING

\section{Radiation dose to patients from} extracorporeal shock wave lithotripsy

SIR,-We would like to point out that extracorporeal shock wave lithotripsy using the Dornier lithotripter as described by $\mathrm{Mr} \mathrm{C} \mathrm{R} \mathrm{Charig} \mathrm{and}$ colleagues (29 March, p 880) is a procedure whích necessitates a high radiation dose to the patient. No published data on the radiation doses received by patients during the procedure are presently available and we report here the results of measurements which we have made on a series of 33 patients treated on the Dornier lithotripter at St Thomas's Hospital.

Measurements were made by thermoluminescent dosimetry of the incident skin doses received from both of the $x$ ray beams of the stereoscopic localisation system. The radiation doses to the skin had a mean value of $12 \mathrm{cGy}$ (rad) (range 2-53 cGy).

Two exposure techniques are used: conventional TV fluoroscopy (mean screening time $218 \mathrm{~s}$, range 23-521 s) and "snapshots"-radiographic exposures which give a higher quality still picture on the TV image storage system (mean number of snapshots 22, range 4-59). High exposure factors are necessary since the beams pass obliquely through the patient. These figures do not include one patient whose calculus was exceedingly difficult to localise and who was obviously an atypical case ( $145 \mathrm{cGy}$ to left side, $107 \mathrm{cGy}$ to the right side, $682 \mathrm{~s}$ screening time, 168 snapshots). These radiation doses are comparable with those received from other high dose $x$ ray procedures such as cardiac catheterisation. ${ }^{1}$

Several other commercial extracorporeal shock wave lithotripsy machines are now being introduced, some of which use ultrasound rather than $x$ rays for localising calculi at the system's pressure focus. ${ }^{2}$ This has the advantage of reducing both the radiation hazard and the cost of the equipment compared with systems that rely on $x$ rays. However, $x$ rays would still appear to have the edge over ultrasound in terms of the ease of localisation and of the clarity in monitoring disintegration of the calculus.

J E SAUNDERS D J EARLE

J C PORTER A J Coleman

Department of Medical Physics,

St Thomas's Hospital,

London SE1 7EH

1 Gough JH, Davis R, Stacey AJ. Radiation doses delivered to the skin, bone marrow and gonads of patients during cardiac catheterisation and angiocardiography. $\mathrm{Br} f$ Radiol 1968;41: 508.

2 Martin X, Mestas JL, Cathignol D, Dubernard JM. Ultrasound localisation for shock-wave lithotripsy. Lancet 1985;ii: 1005.

Assessing exercise capacity in chronic heart failure

SIR,-For some time we have been using the six minute walking test to assess objectively the exercise capacity of elderly patients and monitor their response to treatment (8 March, p 653). Previously we had found few patients aged over 70 years who would consent to bicycle or treadmill testing, and maximal or near maximal exercise was rarely achieved. Most, however, can attempt the six minute walk, which has the advantage of being performed in any level corridor without the need for special equipment. Compliance is generally excellent, and, although we routinely repeat the test once with a resting period between attempts, we find that the difference in distance walked in successive tests is rarely significant.

During the past two years we have used serial walking tests to monitor the response of patients 